\title{
ARTIGO DEFINIDO: SINTAXE OU PRAGMATICA?
}

\author{
Lígia Negri \\ Universidade Federal do Paraná
}

\begin{abstract}
RESUMO
O presente artigo discute a natureza pragmática do artigo definido e propóe que o critério para a caracteri. zação e delimitação dessa categoria seja a sua natureza dêitica.
\end{abstract}

Gostaria de discutir, neste artigo, o estatuto da categoria dos artigos em português, mais precisamente a natureza do artigo definido, que é apresentada como uma subcategoria dessa classe única subdividida conforme o critério de maior ou menor "definição".

De uma maneira geral, como os elementos lexicais que correspondem a essa classe são reduzidos, é muito comum que os gramáticos, ao invés de explicitarem tal classe segundo a sua natureza ou função, apresentem apenas uma lista desses itens lexicais. Esse procedimento permite ao usuário identificar com clareza um ou outro artigo, sem saber ao certo qual o papel que eles desempenham na língua.

Pretende-se destacar, aqui, o papel do artigo definido caracterizando-o conforme a sua natureza e distingui-lo do indefinido, já que ambos apresentam estatuto e funções diferentes.

Cullioli, Fuchs e Pêcheux, a propósito do tratamento formal da linguagem e da aplicação deste aos determinantes, já discutem essa diferença de funções. Para os autores, o artigo indefinido das línguas naturais efetua uma operação de extraçāo, i.e., a de extrair um elemento discreto qualquer de um conjunto dado, enquanto que o definido, os demonstrativos e os possessivos executam a operaçăo de flechagem (indicação), i.e., a de distinguir um individuo já isolado de 
sua classe, ou seja, particularizar um elemento já previamente extraido. ${ }^{1}$

Ex.:

(1) João viu $u m$ soldado. (extração)

(2) João viu o soldado. (flechagem)

Ainda, segundo os autores, a operação de flechagem pode ser de dois tipos:

a) flechagem situacional - em que o locutor designa um elemento presente para os dois interlocutores na situação não expressa linguiisticamente:

(3) Olhe o cachorro. (cachorro localizado pela situação)

b) flechagem contextual - em que o locutor designa um elemento já presente no discurso, seja já mencionado na cadeia anterior (flechagem contextual para trás):

(4) Eu vi um homem atravessar a rua. $O$ homem levava um guarda-chuva.

seja mencionado na seqüência do discurso (flechagem contextual para frente):

(5) Eu vi o homem que levava um guarda-chuva.

Esse tratamento corresponde ao que é usualmente conhecido como dêixis para o primeiro caso, e anáfora e catáfora, respectivamente para o segundo e terceiro.

Da mesma forma que os autores em questão, também E.Ilorach aponta uma diferença nitida entre as funções desempenhadas por ambos os artigos.?

O autor, num estudo que faz sobre o espanhol, analisa a tradição acadêmica que interpreta o valor e a função do artigo definido em dois sentidos - a determinação e a substantivação.

A primeira, que serve para circunscrever a extensão do nome ao qual se antepōe, considera o artigo como elemento "determinante" e obriga, como corolário, a compreender os outros elementos como indeterminados ou indefinidos, obtendo-se assim uma escala de determinação do nome de mais para menos: o livro, um livro, livro.

$O$ artigo indefinido, segundo ele, funciona como um apresentador, como um classificador; não está ligado morfologicamente como signo dependente a um nome; e, pode ocorrer como núcleo de SN; enquanto que o definido não pode ocorrer sozinho e depende da existência de um elemento autônomo, o nome, com o qual constitui um SN unitário dentro da oraçāo.

1 CULLIOLI. A.; C. FUCHB \& M. PECHEUX "Considerations theórtaues a propos du traitment formel du langage", in Documents de linguistique quantitative 7 . Centre de Iinguls. tIque Quantitativa de la Faculté des 'Sciences de L'Université de Parts, 1970.

2 LLRACH. E.A. Estudios do oramatica funcional del cspañol. Madrid. Gredos. 1970. 
Llorach objeta que $u m$ não pode ser considerado como artigo, ainda que apareça nos mesmos contextos em que $o$. Muitas vezes, $u m$ comporta-se como pronome indefinido e alterna-se com outros elementos dessa categoria: $u m$ dia, certo dia; admite artigo: el uno; opōe-se a nenhum; e é substantivável: uno ha traído esa carta. ${ }^{3}$

Observemos ainda os casos de: o verde, a nova, os recentes, nos quais o artigo atua como nominalizador do sintagma adjetivo seguinte e não se constitui como termo autônomo; e os de um verde, uma nova, uns recentes em que o artigo um atua como sintagma nuclear e os adjetivos são termos adjacentes.

Para Llorach a relação morfológica do definido com o nome não é menos ligada do que a do indicador de plural, por exemplo. Já o indefinido pertence, segundo ele, a um grupo de adjetivos chamados quantificadores, que possuem uma mobilidade limitada dentro do SN.

Ex.: três flores azuis $\mathrm{x}$ *azuis três flores uma manhã fria $x{ }^{*}$ fria uma manhã.

Esses quantificadores podem ser de dois tipos: determinados ou "numerais", e imprecisos ou "indefinidos".

Para o autor, contudo, o artigo definido, em espanhol, não se opōe morfológica, funcional, nem gramaticalmente ao indefinido, mas sim a sua própria ausência. A esse respeito ele apresenta a seguinte consideração:

quiero el pan - quiero pan, - entró en la casa entró en casa, constituem a categoria que chamamos 'artigo', e na qual, segundo se observa, existem dois termos que se opōem: um positivo (cujas expressões são/o, a, os, as/ dependendo das relaçōes sintagmáticas) e outro negativo (cuja expressão é/zero/). Em termos tradicionais: 'artigo definido' e 'ausência de artigo' (p. 167).

Todo nome, segundo o autor, pode apresentar essa dupla variação entre /zero / e /artigo definido/, em geral quando o SN funciona como 'complemento', porém menos frequientemente, quando funciona na posição de sujeito.

Quanto à presença e ausência do artigo, Llorach ressalva que em alguns casos a presença é necessária, como em:

El perro ladra $x$ Ladra perro

Lee el libro $x$ "Lee libro

Miraba el paisaje $x{ }^{*}$ Miraba paisaje

3 Alguns exemplos, referentes a anallse de E. Llorach, foram mantidos em espanhol, como no texto original, por fldelldade de emprego, Sua respectiva traducho para 0 portugués nem sempre apresenta as mesmas caracteristlcas. 
Entretanto a variação artigo definido e zero reaparece quando tais exemplos vão para o plural, o que leva a crer que não há condicionamento por parte das funçōes oracionais:

Los perros ladram $x$ Ladram perros

Paralelamente a essas distinçōes apresentadas pelos autores citados, quanto às diferentes funções realizadas por ambos os artigos, cumpre observar que a descrição do papel desempenhado pelo artigo definido merece maiores esclarecimentos."

Assim, ainda de acordo com a análise de E.Llorach, a segunda função do artigo definido, apontada pela tradição acadêmica, é a sub́stantivação - o artigo se une a outras partes da oração que se usam ocasionalmente com valor de substantivos.

A esse respeito ele admite que o artigo definido apresenta dois valores:

a) converte o nome classificador (de classe - nome comum - pois não identifica a realidade, mas a classifica de forma diferente em relação a outras) em nome identificador (nome próprio - por natureza - pois identifica, sem ambiguiidade possivel, uma dada situação, uma realidade determinada). Ex.:

roupa de criança / roupa da criança.

b) conduz à função nominal os segmentos que originariamente desempenham outra função:

é de madeira / é a de madeira,

é mau / é o mau.

O que parece importante reter da análise proposta por Llorach é que a relação do artigo definido não é com o indefinido, mas com a própria ausência do definido. Essa presença ou ausência é que irá determinar o valor do definido e, ainda mais, ligá-lo pragmaticamente com o uso que o falante faz da língua.

Já que o artigo não desempenha por si só uma função na oração, sua presença ou ausência depende, ao contrário, da situaçāo ou do contexto, em última análise de como o falante enfoca a experiência que comunica. 5

O autor irá afirmar que a função do artigo (definido) é assinalar a existência efetiva daquilo designado pelo nome,

4 Oartigo Indefinido também spresenta uma diversidade do cmpregos, ainda que de natureza diferente dos do definido. Entretanto, como já frisamos no inicjo deste trabatho, Iremos nos flxar apenas nas características do definido.

5 LLORACH. p. 169. 
enquanto este, isolado, sem artigo, refere-se à essência que designa (deixou filhos e mulher, frente a deixou os filhos $e$ a mulher).

Não é em qualquer posição do SN que a distinção presença/ausência do artigo definido é tão clara. A posição em que esse SN ocorre ora reforça a distinção na significação, ora atenua.

(6) Isto é cheiro de rosa.

(7) Isto é cheiro da rosa.

(8) Povo tem fome.

(9) O povo tem fome.

Os enunciados (6) e (8), sem artigo definido, apresentam uma interpretação genérica, enquanto nos enunciados (7) e (9), em que há artigo definido, a interpretação se modifica, havendo ai uma leitura individualizante para o SN. Em (6) pode-se estar falando de um cheiro que se assemelha ao da rosa, sem que haja a necessidade da presença desta para a liberação do odor, basta que haja algo no local que cheire como rosa. No entanto em (7) a interpretação obrigatória é a de que o cheiro é da rosa que se encontra em algum lugar próximo de onde exala o odor.

O par (8) e (9) tem uma leitura diferente da apresentada para o anterior. No caso de (8) e (9) temos uma leitura genérica para ambos os enunciados, contudo o falante aponta para uma nuance de significação quando o SN tem artigo definido e quando nāo tem, atribuindo uma interpretação localizada, extensional, para a ocorrência com artigo, e uma meramente "predicativa", intensional, para aquela que não traz artigo algum.

O que os exemplos recém-discutidos demonstram é que embora a distinção entre definido e zero não seja sempre muito marcada, ela é percebida pelo locutor. A posição de sujeito é a que mais neutraliza tal oposição, principalmente se forem extraídas - como no caso dos exemplos (8) e (9) - outras marcas de especificação do enunciado como tempo verbal, indiciais, ${ }^{6}$ modificadores nominais, etc. Mas, mesmo nesses casos, uma variação semântica é identificada pelo locutor, que parece corresponder exatamente a um vínculo extensional implicado pelo uso do definido, e na supressāo desse vínculo quando da sua ausência.

Essa vinculação extensional do artigo definido, mesmo em ocorrências genéricas, deve-se à natureza dêitica, pragmática do próprio artigo. As expressões que ocorrem sem artigo,

6 Sobre os indiclals. para malores detalhes, veja-se BAR-HILLEL, $Y$. Expressós indlcjals. In: DABCAL, M., org. Fundamentos metodológicos da lingülstiea. Camplnas, 1982 , v.4 p. 23 \& 49. 
$\phi N$, atestam apenas a compatibilidade de predicação entre uma certa propriedade e um conceito determinado, ao passo que as expressões introduzidas por artigo definido atualizam um enunciado lingüístico, isto é, instanciam pragmaticamente o enunciado em questãc, fazendo menção clara aos elementos que constituem a classe do conceito referido, a sua extensāo.

O artigo definido, entretanto, é considerado como elemento único de uma classe, tendo como "parente" o artigo indefinido (determinante não-especifico). Essa afinidade, contudo, pode ser contestada pela diferente natureza de ambos e pelas diferentes funções que desempenham no discurso.

A distinção entre ambos os artigos pode ser observada também com relação à sua distribuição. Aparentemente, podem ocorrer nos mesmos contextos; nāo podem, no entanto, apresentar a mesma distribuição em:

a) numa expressāo com qualquer:

(10) Pegue um livro qualquer.

(11) Pegue um qualquer.

(12) *Pegue o livro qualquer.

(13) *Pegue o qualquer.

e b) em casos do tipo:

(14) $U m$ menino esteve aqui ontem. $U m$ menino trouxe os livros que você pediu.

Esse emprego só é possível se as ocorrências de 'menino' referirem-se a indivíduos diferentes, e nesse caso a construção mais comum é a coordenação:

(14') Um menino esteve aqui ontem e um menino trouxe os livros que você pediu.

ou ainda:

(14") Um menino esteve aqui ontem e um trouxe os livros que você pediu.

Nesse caso o que ocorre é uma questão que coloca em jogo noções como tema e rema, i.e., a informação nova ou redundante. O que é importante na segunda oração é a informação nova, tema, e os termos conhecidos ou redundantes, rema, podem ser suprimidos. (14") apresenta também uma das características do indefinido, já citada aqui e apontada por Llorach, que é a sua possibilidade de ocorrer como elemento nuclear do sintagma, caracteristica que o distingue do definido, que não a possui.

Contudo, se no enunciado (14) se pretende falar do mesmo menino, quando da segunda ocorrência do SN: um menino, entāo é imperioso que em tal SN ocorra o determinante definido, ou outros determinantes demonstrativos. 
(15) Um menino esteve aqui ontem. $O$ menino trouxe os livros que você pediu.

ou

(16) Um menino esteve aqui ontem. Esse menino trouxe os livros que você pediu.

Existe, no caso de enunciados do tipo (14), uma regra de dependência, em português, quanto ao uso de determinantes na segunda ocorrência do SN. O artigo definido (ou outro anafórico) é obrigatório em casos como (15), que apresentam correferencialidade e menção prévia do nome sobre o qual já operou o indefinido. A gramática tradicional, quando do tratamento dos artigos, não prevê essa relação necessária.

As diferenças distribucionais entre os determinantes irão se dar com relação a suas possibilidades combinatórias. Entre eles não há possibilidade de co-ocorrência de elementos integrantes da mesma categoria. Existe, na língua, uma seleção paradigmática de $u m$ elemento apenas da categoria escolhida.

O artigo definido, quando numa relação combinatória, aparece em distribuição complementar com outros demonstrativos e sofre as mesmas restrições de ocorrência que estes.

(17) Cada um deve preservar a natureza.

(18) Cada pessoa deve preservar a natureza.

(19) Cada pessoa dessas deve preservar a natureza.

(20) Cada uma dessas pessoas deve preservar a natureza.

(22) "Cada a pessoa deve preservar a natureza.

A impossibilidade de co-ocorrer com elementos demonstrativos e a suscetibilidade à mesma restriçăo dos demonstrativos em relação a outros determinantes, parece reforçar a hipótese de que o artigo definido apresenta uma marca dêitica/demonstrativa muito forte..$^{i}$ Essa remissão às instâncias discursivas não tem a mesma característica de outros elementos dêiticos, ou mesmo dos demonstrativos. Estes estabelecem uma relação com os elementos da situação que permite identifícá-los através do parâmetro da proximidade. $\mathrm{O}$ artigo definido, ao contrário, é neutro quanto a parâmetros de identificação, o que não quer dizer que ele não expressa nada. Ele expressa uma relação precisa entre o enunciado e o contexto, o que permite a identificação clara do item referido por parte do alocutário; a identificação não é um ato lingüístico, vai-se dar fora da linguagem, na situação.

7 Essa caracteristlca déltfco-demonstrativa do artico definido pade ser referendada historicamente: "A orizem do artigo definido em Porugues do demonstrativo latino illu, illa pode ser comprovada pela conservacho do l nas varias linguas romanicas: ir. Ie, la; prov. Io, la; cast. el; lo, la; it. il, lo, la, lnclustre na forma arcafea do Português." COUTiNho. 1.L. Cramática Histórica. RJ. Lrr. Academics. 1969. 
A diferença entre o definido e o indefinido não é dada pela maior especificidade de um em relação ao outro, mas sim pela natureza pragmática que aquele apresenta e esse não. $O$ indefinido é um elemento de constituição da linguagem e o definido de instanciação dela.

$O$ artigo definido pode apresentar inúmeros empregos, i.e., pode ocorrer em expressões que podem ser caracterizadas como referenciais, anafóricas, atributivas, genéricas e puramente dêiticas.

No caso de enunciados que apresentam expressões numa utilização referencial individualizante podemos observar os que se seguem:

(23) O diretor dos filmes "Cenas de um casamento" e "Face a Face" já pode voltar para a Suécia.

(24) $O$ pai de José está muito doente.

(25) Morre o papa.

(26) O Sena está poluído.

(27) Fechado o Congresso.

(28) $O$ carro que te mostrei já foi vendido.

(29) A - Seu filho está aí.

$\mathrm{B}$ - Deixe o menino entrar.

(30) $O$ seu livro caiu.

Pode-se fazer uma utilização referencial individualizante de expressões introduzidas por artigo definido, garantida por uma forma de identificação inequivoca dessa expressão. Essa garantia pode ser dada pelo contexto discursivo, lingüístico, anterior ou posterior - anáfora ou catáfora - como em (29) e (28), respectivamente.

A individualização também pode ser feita levando-se em conta a situação extra-lingüística, a indicação situacional, como (30), que apresenta um uso dêitico.

Há ainda outro tipo de garantias de individualização que são culturais, tais como (25), pois só há um papa.

Observemos alguns usos tipicamente genéricos:

(31) $O$ homem moderno é escravo da máquina.

(32) $A$ abelha $\dot{e}$ dotada de antenas e ferrão.

(33) $O$ morador dos grandes centros urbanos está morrendo vitima da poluição.

(34) $O$ peixe vive no mar.

(35) O homem viveu muitos anos em cavernas, e comparemo-los com (36):

(36) O ganhador da loteria é um felizardo.

Geralmente frases como (36) são ambíguas, podem ter tanto a leitura generalizante, como uma interpretação atributiva.

Parafraseando (36) podemos ter: 
(36a) Qualquer que seja $x$, se $x$ ganha na loteria, $x$ é um felizardo. (genérico).

(36b) $\mathrm{X}$ ganhou na loteria, $\mathrm{x}$ é um felizardo (não importa quem $x$ seja). (atributivo).

Vejamos outros casos de uso atributivo de expressōes com artigo definido:

(37) $O$ vencedor do torneio ficará com a taça e um prêmio em dinheiro. (PP. situacional: todo torneio tem um vencedor).

(38) O professor que vier deverá integrar a comissāo da Biblioteca. (identificação catafórica: - que vier).

(39) Quero que o aluno que fez isso se apresente ao diretor. (identificação catafórica: - que fez isso).

(37), (38) e (39) não constituem usos referenciais de expressōes com artigo, mas permitem o uso do definido porque há outras marcas no enunciado que especificam a expressão.

Quanto ao anafórico, pode-se encontrar um uso anafórico com definido que seja referencial como (29) ou não, como o exemplo abaixo:

(40) Um menino qualquer desses que estão na praça pode levar esse livro prá você. $O$ menino certamente exigirá uma gorjeta.

Nesse caso não há correferencialidade, ou pelo menos, fica difícil falar nela.

Temos ainda, para fechar o quadro, os usos exclusivamente dêiticos do definido.

(41) Espere um pouco, a moça vai trazer o café. (a que sempre traz e nós sabemos quem é).

(42) $O$ homem foi atropelado. (Esse homem aí).

(43) Você pergunta enquanto a gente fecha o livro. (cada um fecha o seu).

(44) O escândalo $d a$ Vale (manchete - Veja 19-03-80 todos sabem qual é o escândalo, e que é da Cia. Vale do Rio Doce).

O que podemos depreender desses exemplos é que o que determina esta ou aquela interpretação para uma expressão iniciada por artigo definido, não é uma especificaçāo própria do artigo, mas sim um conjunto de circunstâncias, linguiísticas ou não, que permitem esta ou aquela interpretaçāo.

Com base nas ocorrências do artigo definido apresentadas, e da sua relação com o indefinido, ou mesmo com a ausência de ambos, pode-se observar que:

a) não há função, nem natureza comuns que permitam considerar os artigos definido e indefinido como elementos da mesma categoria. 
b) há uma diversidade de usos para o artigo definido e seria interessante encontrar um critério comum que os agrupasse e que caracterizasse tal artigo.

Dessa forma, pretende-se tratar o artigo como um elemento dêitico cuja função específica se constrói no interior do compromisso pragmático entre os interlocutores do discurso. $O$ artigo definido, segundo esse ponto de vista, remete a um compromisso pragmático que tende à identificação de um referente através de um vínculo dos interlocutores com a enunciação.

Essa caracteristica indicial do artigo será neutralizada ou reforçada por outras marcas lingüísticas do enunciado.

Não se pretende adotar, aqui, um ponto de vista referencial, porque o definido não apresenta necessariamente tal vínculo, conforme pode ser corroborado pelos exemplos.

Cumpre ainda esclarecer em que acepção o termo dêixis está sendo considerado. ${ }^{8}$ Segundo a classificação proposta proposta por M. Lahud, descarta-se a dêixis enquanto ostensão, e também a referencial, assumindo-se a relação da dêixis com a enunciação. Ainda segundo Lahud, a relação dêixis/ anáfora neutraliza-se sob a concepção referencial, que considera que há nesse caso uma variação do grau da função e não de sua natureza. Dessa forma, se os dêiticos são concebidos como indicadores referenciais, atribui-se a mesma função aos anafóricos - num caso é a situação extra-lingüística que determina o referente do indicador, no outro é o contexto linguístico (contexto e cotexto, respectivamente). Sua função genérica é a designação de um individuo.

A concepção da dêixis do ponto de vista da enunciação estabelece uma relação entre o enunciado e o sujeito que o enuncia, e o que diferencia a dêixis da anáfora é a natureza diferente de cada operação.

Entretanto, se considerarmos a seguinte proposta de C. Franchi a respeito da produção e determinação de um discurso, déixis e anáfora podem ser encaradas como operaçōes com a mesma natureza, no interior de uma concepção enunciatória de dêixis. ${ }^{\circ}$

Franchi postula que um discurso $\mathrm{Dj}$ condiciona um discurso Di, determinando sobre Di certas modificações:

$\mathrm{Dj} \longrightarrow \mathrm{Di}$ onde: $\mathrm{Dj}$ é anterior a $\mathrm{Di}$.

Essa sobredeterminaçāo, ainda segundo o autor, não se verifica apenas para a seleção induzida de um certo conjunto de invariantes semânticos e retóricos (invariantes no proces-

8 Para uma flsto mais detalhads sobre a caracterizacio da délxls, ver LAFUD, M. A propbsito da nogato de déixis Băo Paulo. Atıcs. 1975.

9 FRANCHI. C. Hypotheses pour une rocherche on syntaxe. 1971, Maltrlse, Unlversite de Provence. Alx-en-Provence. 
so colocado em jogo). Ela ainda tem consequiências sintáticas. $\mathrm{E}$ caso da anáfora, condicionada por ocorrência anterior dos elementos lexicais aos quais os anafóricos associam o segundo enunciado.

Levando-se em conta a concepção de C. Franchi em que um discurso lingüístico, que determina os processos anafóricos, deve estar incluído nas condiçōes de produção do próximo discurso, pode-se chegar à conclusão de que dêixis não é diferente de anáfora, identificam-se como um mesmo processo.

Pode-se optar então por uma linha teórica pragmática para explicar a natureza e funcionamento do artigo definido e considerar os vários usos como concernentes à mesma função básica - a déitica - considerando que também o discurso linguiistico passa a fazer parte do contexto, i.e., das condições de produção do discurso seguinte. A operação de indiciação da expressão contendo artigo definido aponta quer para o contexto, quer para o co-texto.

Dai a razão da proposta para o tratamento do artigo definido falar em natureza dêitica do artigo e considerá-la como a marca fundamental.

Esse traço é que irá caracterizar o definido e distingui-lo dos demais determinantes, e é o reconhecimento de tal traço que permite aos interlocutores a identificação do referente de uma tal expressão. Essa característica pragmática do definido é ora reforçada por outras marcas da enunciação no enunciado, como instanciação verbal, adverbial, etc, ora neutralizada pela ausência dessas marcas.

A variedade de usos das expressões contendo definido, de genérica a referencial, deve-se exatamente à ocorrência do artigo definido com outras marcas pragmáticas no enunciado. A variedade de usos do artigo definido é resultado, portanto, da associação dessas marcas pragmáticas do enunciado e não é inerente à natureza do artigo definido.

Portanto, um modelo teórico que não leve em conta a pragmaticidade da linguagem, os seus contextos de utilização, não pode tratar adequadamente elementos como o definido e outros que apresentam essa marca característica. 


\section{REFERENCIAS BIBLIOGRAFICAS}

1 BAR-HILLEL, Y. "Expressões Indiciais" em M. Dascal, org. 1982 Fundamentos Metodológicos da Lingǘstica. vol. IV - Pragmática. Campinas, edit. pelo organizador, 1982.

2 CULIOLI, A., C. FUCHS e M. PECHEUX "Considérations theoriques à propos du traitement formel du langage.", in Documents de linguistique quantitative 7 . Centre de Linguistique Quantitative de la Faculté des Sciences de L'Université de Paris, 1970.

3 FRANCHI, C. Hypothèses pour une recherche en syntaxe. Dissertaçāo de Mestrado. D. E. S. de Linguistique Française. Université de Provence. 1971.

4 LLORACH, E. A. Estudios de Gramática Funcional del Español. Madrid, Editorial Gredos S. A., 1970.

5 LYONS, J. Semantics. vols. 1 e 2. Cambridge, Cambridge University Press, 1977.

6 NEGRI, L. A natureza dêitica do artigo definido. Dissertação de Mestrado. Departamento de Linguiistica do Instituto de Estudos da Linguagem. UNICAMP, Campinas, 1986. 